\title{
PRESERVATION OF ENDOTHELIUM-DEPENDENT VASODILATION WITH LOW-POTASSIUM UNIVERSITY OF WISCONSIN SOLUTION
}

Jeongryul Lee, MD

Davis C. Drinkwater, Jr., MD

Hillel Laks, MD

Albert Chong, MS

Arie Blitz, MD

Mary A. Chen, BS

Louis J. Ignarro, MD

Paul Chang, BS
University of Wisconsin solution has provided excellent myocardial preservation. However, the high potassium content of the currently available University of Wisconsin solution has been implicated in coronary artery endothelial damage. We placed 16 neonatal (age 1 to 3 days) Duroc piglet hearts on an isolated nonworking perfusion circuit. Endothelium-dependent and endothelium-independent vasodilation were tested by measuring coronary blood flow after intracoronary infusion of bradykinin $\left(10^{-6}\right.$ $\mathrm{mol} / \mathrm{L})$ and nitroprusside $\left(10^{-6} \mathrm{~mol} / \mathrm{L}\right)$, respectively. In addition, nitric oxide levels were measured after bradykinin infusion. The hearts were then arrested blindly with either a modified University of Wisconsin solution (group 1; $n=8, \mathrm{~K}^{+}=25 \mathrm{mEq} / \mathrm{L}$ ) or standard University of Wisconsin solution (group $2 ; n=8, \mathrm{~K}^{+}=129 \mathrm{mEq} / \mathrm{L}$ ) by infusion of cardioplegic solution every 20 minutes for a total of 2 hours. After bradykinin infusion, the mean coronary blood flow increased by $237.1 \% \pm 14.0 \%$ of baseline valves before arrest and by $232.8 \% \pm 16.0 \%$ after arrest in group 1 ( $p=$ not significant). As in the first group, the mean coronary blood flow in group 2 increased by $231.1 \% \pm 13.7 \%$ before arrest; however, the increase in mean coronary blood flow after arrest was significantly attenuated $(163.3 \% \pm$ $12.8 \%, p<0.01$ ). The loss of endothelium-dependent coronary blood flow response in group 2 correlated with a decreased capacity to release nitric oxide after arrest (prearrest $8.25 \pm 2.30 \mathrm{nmol} / \mathrm{min}$ per gram versus postarrest $-2.46 \pm 2.29 \mathrm{nmol} / \mathrm{min}$ per gram, $p<0.01$ ). Endotheliumindependent vasodilatory response revealed no significant difference between groups before and after arrest. These results suggest that the low-potassium University of Wisconsin solution provides superior protection of the endothelium by preserving the endothelium-dependent vasodilatory response to nitric oxide release. (J Thorac Cardiovasc Surg 1996;112: 103-10)
T he University of Wisconsin solution (UWS), developed by Wahlberg, Southard, and Belzer ${ }^{1}$ in 1986, has been used successfully to preserve the pancreas, ${ }^{2}$ kidney, ${ }^{3}$ and liver ${ }^{4}$ in both laboratory and clinical settings. Numerous studies have demonstrated that UWS also provides excellent myocardial preservation in a variety of animal models. ${ }^{5-8}$ Fur-

From the Division of Cardiothoracic Surgery, UCLA Medical Center, Los Angeles, Calif.

Received for publication July 3, 1995; accepted for publication Sept. 5, 1995.

Address for reprints: Davis C. Drinkwater, Jr., MD, Division of Cardiothoracic Surgery, Room B2-375 CHS, UCLA Medical Center, 10833 LeConte Ave., Los Angeles, CA 90095.

Copyright (c) 1996 by Mosby-Year Book, Inc.

$0022-5223 / 96 \$ 5.00+0 \quad \mathbf{1 2 / 1 / 6 9 0 6 3}$ thermore, clinical trials at various centers have proved that UWS is a safe and effective preservation solution for human cardiac transplantation., ${ }^{9,10}$ These studies have demonstrated favorable effects of UWS on the myocyte but have not focused on its effects on either the conduction tissues or endothelium. Moreover, the optimum concentration and composition of its components have not been standardized. The high potassium content $(129 \mathrm{mmol} / \mathrm{L})$ of UWS has been suspected of damaging the endothelium during preservation.

Potassium is a recognized vascular irritant, and it has been shown to cause marked arterial endothelial damage.$^{11}$ Carpentier, Murawsky, and Carpentier ${ }^{12}$ have demonstrated the endothelial cytotoxicity of hyperkalemic crystalloid cardioplegic solutions to endothelial cells in tissue cultures. We recently 
presented our clinical results that demonstrated twice the prevalence of accelerated graft atherosclerosis at 24 months after transplantation in the patient group that received UWS $(21 \%, n=100)$ compared with the Stanford solution group (10.5\%, $n=100$ ). Although UWS contributes significantly to successful myocardial functional recovery after storage, numerous laboratory studies have shown that UWS and other hyperkalemic cardioplegic solutions fail to preserve endothelial function. ${ }^{13-16}$

The endothelium plays a significant role in vasoregulation and coagulation homeostasis; it produces prostacyclin, plasminogen activator, antithrombin III, and endothelium-dependent relaxation factor (EDRF). ${ }^{17,18}$ EDRF, which has been demonstrated to be nitric oxide (NO), ${ }^{19}$ has major effects on local vasoregulation by modulating vascular tone and inhibiting platelet aggregation and adhesion. ${ }^{20,21}$ Endothelial damage during preservation exposes collagen fibers and the basement membrane and also induces the release of procoagulants. ${ }^{22}$ Therefore disruption of the endothelium, and hence its normal physiologic functions, may have deleterious effects on myocardial perfusion, vascular permeability, endothelium-platelet interactions, and, consequently, the long-term outcome after cardiac transplantations.

We hypothesized that by decreasing the potassium content of the UWS we might improve preservation of endothelial function. A previous study in our laboratory has shown that a modified lowpotassium ( $25 \mathrm{mmol} / \mathrm{L}$ ) UWS and the standard high-potassium UWS provide equivalent myocardial functional preservation. ${ }^{23}$ The purpose of this study, therefore, was to examine and compare the effects of the potassium level on endothelial function by preserving hearts with either the standard highpotassium or the modified low-potassium UWS.

\section{Material and methods}

Experimental preparation. Hearts were harvested from 12 neonatal ( 1 to 3 days old) piglets (Duroc) without intervening ischemia and placed on an isolated, nonworking, blood-perfused circuit (Fig. 1). Adolescent Duroc pigs (50 to $70 \mathrm{~kg}$ ), used as cross circulation support, were anesthetized with intramuscular ketamine $(100 \mathrm{mg} / \mathrm{kg})$ and acepromazine $(0.1 \mathrm{mg} / \mathrm{kg})$. Continuous intravenous pentobarbital diluted in $5 \%$ dextrose $(5 \mathrm{mg} / \mathrm{ml})$ and supplemented with boluses of pentobarbital through the femoral vein was administered for maintenance anesthesia. Mechanical ventilation (Bennet MA-1 ventilator, Puritan-Bennet Corp., Los Angeles, Calif.) at an inspired oxygen fraction of 1.0, a positive end-expiratory pressure of $5 \mathrm{~mm} \mathrm{Hg}$, a tidal volume of 15 to $20 \mathrm{ml} / \mathrm{kg}$, and a rate of 12 breaths/min was established. Arterial blood gas valves were obtained every 30 minutes (model ABL-330, Radiometer, Copenhagen, Denmark) and hematocrit values every hour. The $\mathrm{pH}$ was maintained between 7.40 and 7.50, carbon dioxide tension between 30 and $40 \mathrm{~mm} \mathrm{Hg}$, and oxygen tension higher than $400 \mathrm{~mm} \mathrm{Hg}$. Rectal temperature was maintained at $38^{\circ} \mathrm{C}$ by use of a heated water blanket (Medi-therm, model No. MTA-4700, Gaymar Industries, Inc., Orchard Park, N.Y.). Systolic blood pressure was kept greater than $80 \mathrm{~mm} \mathrm{Hg}$ by intravenous lactated Ringer's standard solution or $6 \%$ hetastarch and the hematocrit level was kept greater than $25 \%$ by providing intravenous blood obtained from a previous support pig.

Blood from the support animal was directed through a roller pump (model 10-40-00, Stokert Instruments, Munich, Germany), warmed to $38^{\circ} \mathrm{C}$ by a blood cardioplegia device (model BCD ADV-1, Shiley Inc., Irvine, Calif.), and delivered through the innominate artery to the aortic root of the harvested heart at a constant mean pressure of $60 \mathrm{~mm} \mathrm{Hg}$. Perfusion and suspension of the heart were achieved by connection of the innominate artery cannula to the blood cardioplegia device while the distal aorta remained clamped. Concurrently, the aorta was cannulated with a 14-gauge perfusion cannula and connected to an open adjustable column to control the coronary perfusion pressure. Silicone rubber tubing $(1 / 4$-inch outer diameter) was inserted into the pulmonary artery to collect coronary sinus effluent and measure coronary blood flow (CBF). Blood from the aortic column and pulmonary artery was returned to the support animal directed through a $40 \mu \mathrm{m}$ blood filter (Ultipor EC3840, Pall BioMedical Products Corp., East Hills, N.Y.).

Pressure monitoring. Fiberoptic transducer-tipped catheter (1.3 mm outer diameter, model 110-4, Camino Laboratories, San Diego, Calif.) was advanced into the left ventricle via the left atrium for pressure monitoring. Aortic root pressure was simultaneously recorded with a fluid-filled transducer (Statham P23, Spectramed Inc., Oxnard, Calif.).

Endothelial function test. After stabilization of baseline CBF (30 to 60 minutes after perfusion), endotheliumdependent vasodilation was tested by administration of bradykinin mixed in arterial blood to a final concentration of $10^{-6} \mathrm{~mol} / \mathrm{L}$ for 1 minute at a constant mean pressure of $60 \mathrm{~mm} \mathrm{Hg}$. Immediately after the infusion, three separate minute volumes of coronary effluent were collected in graduated cylinders, and the average CBF was calculated and expressed as a percent increase in baseline CBF. In addition, $5 \mathrm{ml}$ samples of arterial and coronary sinus blood were obtained immediately after the 1-minute bradykinin infusion for NO level determination.

After return of CBF to a steady baseline level (approximately 30 minutes after bradykinin infusion), endothelium-independent relaxation was tested by infusing sodium nitroprusside mixed in blood to a final concentration of $10^{-6} \mathrm{~mol} / \mathrm{L}$ in the same manner as that of bradykinin, and the average $\mathrm{CBF}$ per minute was expressed as percent increase of baseline CBF before nitroprusside infusion.

The hearts were then arrested with either the modified low-potassium UWS (group $1, n=8, \mathrm{~K}^{+}=25 \mathrm{mEq} / \mathrm{L}$ ) or the standard high-potassium UWS (group $2, n=8, \mathrm{~K}^{+}=$ 


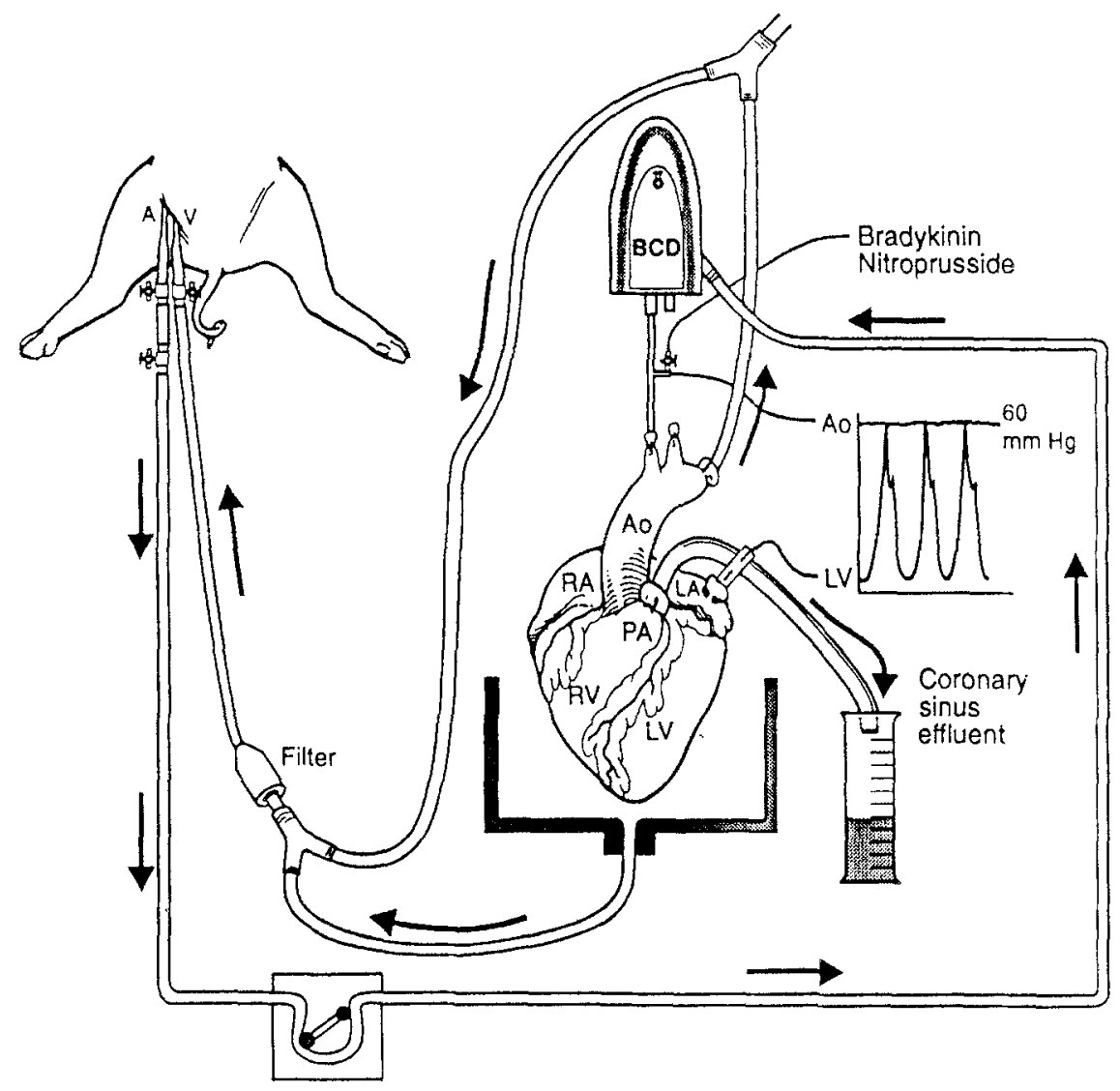

Fig. 1. Diagram of isolated nonworking perfusion circuit. $B C D$, Blood cardioplegia device; $A$, artery; $V$, vein; $A o$, aorta; $R A$, right atrium; $L A$, left atrium; $P A$, pulmonary artery; $R V$, right ventricle; $L V$, left ventricle.

$129 \mathrm{mEq} / \mathrm{L}$ ) delivered at $50 \mathrm{~mm} \mathrm{Hg}$ until arrest and then at $40 \mathrm{~mm} \mathrm{Hg}$ for a period of 2 minutes while topical cooling was provided with iced saline slush. Two-minute doses of cold cardioplegic solution were given at $40 \mathrm{~mm}$ $\mathrm{Hg}$ every 20 minutes. After 2 hours of arrest, the hearts were reperfused with warm $\left(37^{\circ} \mathrm{C}\right)$ unmodified blood at a constant mean pressure of $40 \mathrm{~mm} \mathrm{Hg}$, which was raised to $60 \mathrm{~mm} \mathrm{Hg}$ after the onset of sinus rhythm. After stabilization of baseline CBF (approximately 1 hour after reperfusion), the prearrest experimental protocol with bradykinin and nitroprusside infusion was repeated. NO samples were obtained after the bradykinin infusion.

NO analysis. After collection, whole-blood samples were immediately placed on ice and then centrifuged at $4^{\circ} \mathrm{C}$ for 10 minutes at $3200 \mathrm{rpm}$. The supernatant was obtained and kept at $4^{\circ} \mathrm{C}$. Aliquots of $100 \mu \mathrm{l}$ were then injected into the measuring apparatus and any nitrite or nitrate was rapidly reduced to $\mathrm{NO}$ by vanadium at $98^{\circ}$ C. ${ }^{19,24}$ Oxygen-free purified nitrogen was delivered into a reaction flask and was drawn into the Dasibi Chemiluminescence $\mathrm{NO}_{\mathrm{X}}$ Analyzer (model 2108, Dasibi, Glendale, Calif.) at a constant rate of $200 \mathrm{ml} / \mathrm{min}$ with the aid of a vacuum pump. The detector is sensitive to the nitrogen dioxide radical, the photon-emitting product generated by the reaction between ozone and NO. The analyzer was calibrated before each use with a standard mixture of 825 ppm NO in oxygen-free nitrogen (ScottMarrin, Inc., Riverside, Calif.). Results were expressed in nanomoles per $100 \mu 1$. The arteriovenous difference was then calculated and multiplied by the CBF to obtain the release rate of NO in nanomoles per minute.

Statistical analysis. A two-tailed, paired $t$ test was used to compare the percentage increase in CBF from the baseline value before and after arrest and to compare the release of NO before and after preservation. A $p$ value of less than 0.05 was considered to be statistically significant.

Animal care. All animals were cared for in compliance with the "Principles of Laboratory Animal Care" formulated by the National Society for Medical Research and the "Guide for the Care and Use of Laboratory Animals" prepared by the National Academy of Sciences and published by the National Institutes of Health (NIH Publication No. 86-23, revised 1985).

\section{Results}

Endothelium-dependent vasodilation. The percentage increase of $\mathrm{CBF}$ in response to bradykinin 


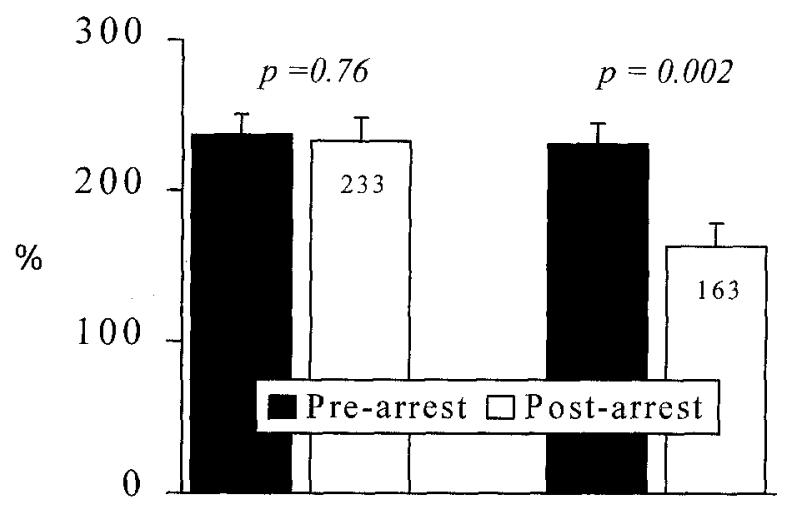

Low $\mathrm{K}$
High K

Fig. 2. Endothelium-dependent vasodilation after bradykinin infusion.

was significant in both groups before arrest: $237 \% \pm$ $14.0 \%$ of baseline in group $1(n=8,15 \pm 1.81$ versus $35.02 \pm 4.13 \mathrm{ml} / \mathrm{min}, p=0.001)$ and $231 \% \pm$ $13.7 \%$ of baseline in group $2(n=8,14.89 \pm 1.03$ versus $31.94 \pm 3.47 \mathrm{ml} / \mathrm{min}, p=0.001$ ). There was no significant difference in vasodilatory response between the two groups $(p=0.58)$. After 2 hours of multidose cardioplegic arrest, the percent increase of $\mathrm{CBF}$ in response to bradykinin was maintained in group 1, in contrast to the result in group 2: the percent increase was $232 \% \pm 16.0 \%$ of baseline in group $1(n=8,22.88 \pm 1.72$ versus $53.06 \pm 5.14$ $\mathrm{ml} / \mathrm{min}$ ) but only $163 \% \pm 12.8 \%$ of baseline in group $2(n=8,24.5 \pm 1.66$ versus $36.38 \pm 1.74$ $\mathrm{ml} / \mathrm{min}$; Fig. 2). There was no significant difference between prearrest and postarrest responsiveness in group $1(p=0.59)$; however, the vasodilatory response to bradykinin was significantly decreased after arrest compared with the prearrest response in group $2(p=0.002)$ (Fig. 2).

NO release. The mean NO release after stimulation with bradykinin revealed no significant difference between prearrest $(8.63 \pm 2.91 \mathrm{nmol} / \mathrm{min}$ per gram) and postarrest values $(8.06 \pm 2.51 \mathrm{nmol} / \mathrm{min}$ per gram; $p=0.88$ ) in group 1 (Fig. 3). In contrast, there was a significant decrease in NO release in the hearts preserved in high-potassium UWS (group 2) after arrest compared with the prearrest level (prearrest $8.25 \pm 2.3$ versus postarrest $-2.46 \pm 2.29$ $\mathrm{nmol} / \mathrm{min}$ per gram, $p=0.005$; Fig. 3).

Endothelium-independent vasodilation. Before cardioplegic arrest, a significant increase of CBF was observed in both groups: $194 \% \pm 7.5 \%$ of baseline value in group $1(14.63 \pm 1.87$ versus $27.96 \pm 3.20$

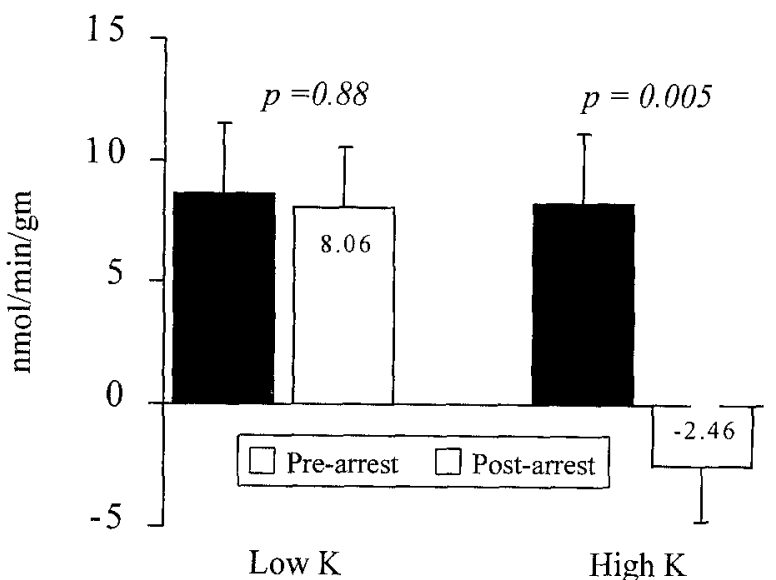

Fig. 3. NO release after bradykinin infusion.

$\mathrm{ml} / \mathrm{min}, p=0.001)$ and $209 \% \pm 13 \%$ of baseline value in group $2(14.06 \pm 1.30$ versus $30.19 \pm 4.20 \mathrm{ml} / \mathrm{min}$, $p=0.001$ ) (Fig. 4). After 2 hours of arrest, the response to nitroprusside remained unchanged in both groups: $187 \% \pm 10 \%$ of baseline value in group 1 $(20.0 \pm 2.49$ versus $36.88 \pm 3.86 \mathrm{ml} / \mathrm{min}, p=0.001)$ and $194 \% \pm 17 \%$ of baseline value in group 2 (16.75 \pm 2.27 versus $30.27 \pm 2.36 \mathrm{ml} / \mathrm{min}, p=0.001$ ) (Fig. 4 ). Endothelium-independent vasodilatory response to nitroprusside revealed no significant difference between groups before and after arrest ( $p=0.33$ for group 1 and $p=0.75$ for group 2; Fig. 4).

\section{Discussion}

Our previous investigations have revealed that multidose UWS containing $129 \mathrm{mmol} / \mathrm{L}$ of potassium is detrimental to endothelial function, ${ }^{24}$ although UWS is generally known to be clinically and experimentally successful in extended solid organ preservation (kidney, liver, pancreas). ${ }^{2-4}$ Studies from numerous laboratories have demonstrated superior functional recovery and ischemic periods of up to 24 hours with the use of UWS. ${ }^{7,8}$ UWS is a formula designed for the induction and safe maintenance of organ preservation for transplantation. Its components are designed to minimize the harmful effects of hypothermic ischemia and subsequent reperfusion. Osmotically active impermeants, that is, lactobionate, raffinose, and pentastarch, have been incorporated to improve myocardial recovery by reducing edema during hypothermic arrest. Other components include allopurinol to reduce oxygen free radical production, glutathione to act as an antioxidant, and adenosine to supply the cell with adenosine triphosphate substrates during reperfusion. ${ }^{25}$ 
Nevertheless, the high potassium concentration of UWS has been implicated in endothelial cell damage, causing vasospasm and increased capillary permeability. ${ }^{26}$ Sellke and colleagues ${ }^{27}$ have shown that the higher concentration of potassium predisposes the myocardial cell to the influx of calcium, thereby increasing wall tension. As the concentration of potassium increases from 30 to $40 \mathrm{mmol} / \mathrm{L}$, the resting membrane potential partially depolarizes, the calcium channel is activated, and influx increases, which results in an energy-consuming semisystolic arrest. Furthermore, the low sodium concentration of UWS (30 $\mathrm{mmol} / \mathrm{L}$ ) may exacerbate the calcium influx, especially during reperfusion. ${ }^{27}$ Mankad, Chester, and Yacoub ${ }^{13}$ reported that rat hearts perfused with cardioplegic solution containing a potassium concentration of 30 $\mathrm{mEq} / \mathrm{L}$ or greater showed decreased endothelial response to vasodilators. Saldanha and Hearse ${ }^{14}$ reported endothelial dysfunction in response to 5-hydroxytryptamine in the rat heart after a 30-minute continuous infusion of $20^{\circ} \mathrm{C}$ cardioplegic solution containing $25 \mathrm{mmol} / \mathrm{L}$ of potassium. He and associates, ${ }^{27 \mathrm{a}}$ however, reported that endothelium of porcine epicardial coronary arteries is relatively tolerant to hyperkalemia-induced injury at a potassium concentration of $50 \mathrm{mmol} / \mathrm{L}$. In contrast, our low-potassium group ( 25 $\mathrm{mmol} / \mathrm{L}$ ) demonstrated that bradykinin-induced endothelium-dependent vasodilatory function is maintained.

The foregoing discrepancy in the literature suggests that other factors, including oxygen level, ischemia or reperfusion, composition and temperature of preservants and reperfusates, and reperfusion pressure, may also influence endothelial function. Ischemia alone can cause endothelial damage, perhaps mediated by oxygen-derived free radicals, resulting in the impairment of endothelium-dependent vasorelaxation caused by EDRF/NO agonists. ${ }^{28,29}$ Reperfusion with unmodified blood impairs endothelial function in coronary arteries subjected to normothermic global ischemia. ${ }^{30}$ Qui, Manche, and Hearse ${ }^{31}$ demonstrated that, after both ischemia and reperfusion with a low-potassium solution $(16 \mathrm{mmol} / \mathrm{L})$, endothelium-mediated vasodilation was attenuated by $50 \%$. Endothelial generation of superoxide radicals may be a trigger mechanism for endothelial dysfunction, which is then amplified by neutrophil adherence and migration into the ischemic region. ${ }^{32}$

Several investigators have examined the effect of temperature on endothelial function. Amrani and colleagues ${ }^{33}$ demonstrated that moderate hypother-

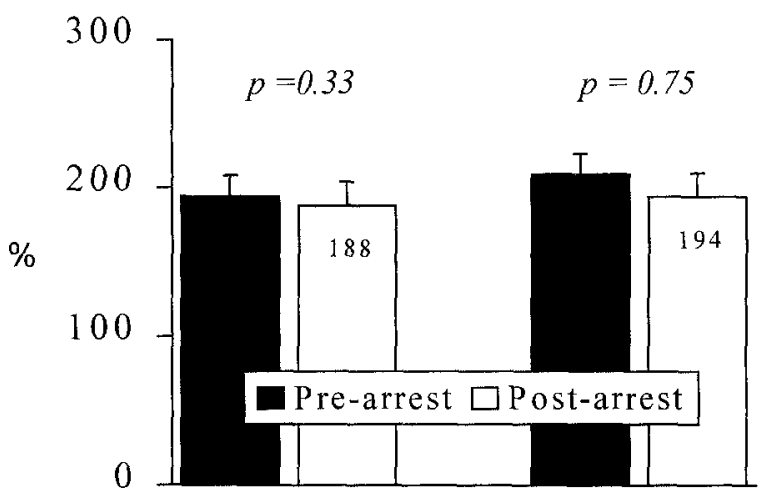

Low $\mathrm{K}$

High K

Fig. 4. Endothelium-independent vasodilation after nitroprusside infusion.

mia $\left(20^{\circ} \mathrm{C}\right)$ and extremely hyperkalemic UWS for cardioplegia $(130 \mathrm{mmol} / \mathrm{L})$ induces a marked increase in coronary vascular resistance that is associated with impaired myocardial protection and the endothelial function is better preserved at $4^{\circ} \mathrm{C}$ than at $20^{\circ} \mathrm{C}^{34}$ Aoki, Kawata, and Mayer ${ }^{35}$ reported excessive cold cardioplegic solution (lower than $4^{\circ} \mathrm{C}$ ) may cause endothelial dysfunction. Mankad, Slavik, and Yacoub ${ }^{36}$ have shown that the optimal temperature to preserve endothelial function after preservation with UWS is at or below $10^{\circ} \mathrm{C}$. Our cardioplegic temperature was maintained at $4^{\circ} \mathrm{C}$; this may have contributed to the preservation of endothelial function in the low-potassium group.

Evora, Pearson, and Schaff ${ }^{37}$ have recently shown that hyperkalemic $(45 \mathrm{mmol} / \mathrm{L})$ crystalloid cardioplegia does not impair endothelial function in isolated canine epicardial coronary arteries subjected to 45 minutes of arrest. They concluded that endothelial damage may be induced by other mechanisms, including high shear stress from large delivery volumes and high infusion pressure. ${ }^{37}$ There is a possibility that high shear stress and pressure to the coronary endothelium during reperfusion impair endothelial function by mechanical dislodgment of weakened endothelial attachments. Sawatari and colleagues $^{38}$ showed that high initial perfusion pressure $(60 \mathrm{~mm} \mathrm{Hg})$ reduced coronary vasodilatory response to acetylcholine stimulation. In the present study, reperfusion was initiated at $40 \mathrm{~mm} \mathrm{Hg}$ and then gradually increased to a mean of $60 \mathrm{~mm} \mathrm{Hg}$ after resumption of cardiac rhythm. ${ }^{38}$ However, it is still unclear whether a pressure of $40 \mathrm{~mm} \mathrm{Hg}$ is low enough to avoid endothelial damage. Further stud- 
ies are necessary to determine the effects of pressure and flow on the endothelium.

Punctuating the variability noted in the literature concerning the multitude of factors that affect endothelial function is our previous report, ${ }^{24}$ which, although corroborating our current findings of endothelial dysfunction with use of conventional UWS, differs in one regard. Whereas our prior study revealed concordant elimination of endothelial response to bradykinin and NO production, our present study noted that the endothelial response was reduced but not eliminated in the setting of absent NO production. It is not clear how these apparent contrasting results can be explained. As discussed in the foregoing paragraphs, many factors influence endothelial function, and some of these factors may have played a hand in our conflicting results. Further study is ongoing to examine the effects of these factors. Nevertheless, it is clear from our studies that endothelial function is adversely affected by higher potassium concentrations in crystalloid cardioplegic solution.

It is interesting to note in addition that, although we found an ongoing but diminished endothelial response to bradykinin stimulation, NO production ceased by our current methods of measurement. Two possibilities exist to account for this discordance. First, bradykinin has known mechanisms of vasodilation that, although endothelium dependent, are independent of NO production. One such mechanism is bradykinininduced generation of prostacyclin, a known vasodilator. ${ }^{39}$ The prostacyclin pathway may have a differential sensitivity to the effects of potassium cardioplegia than NO. A second and alternative explanation is that current methods for measurement of NO may not be sufficiently sensitive to detect the small amounts of NO release capable of inducing vasodilation. It is likely that both these factors are operative in our present study.

It is now apparent that the vascular endothelium is an active organ producing at least several substances that regulate vascular tone. Furchgott and Zawadzki ${ }^{40}$ found a potent endotheliumderived vasodilator that has been subsequently named EDRF. Extensive evidence exists that EDRF is NO itself. However, there are several important differences between these compounds, specifically their chemical characteristics, halflives, sensitivities, and sites of action. ${ }^{19,41,42}$ The principal biochemical mechanism of action of EDRF/NO has been elucidated. Subsequent to its release, NO, a highly reactive simple gas gener- ated from the vascular endothelium, penetrates adjacent smooth muscle cell membranes and binds to the heme portion of guanylate cyclase. Activated guanosine cyclase increases the intracellular cyclic guanosine monophosphate level, which in turn reduces the intracellular calcium concentration. ${ }^{43}$ Sellke and associates ${ }^{44}$ showed that bradykinin induces endothelium-dependent relaxation, which is mediated by EDRF, by demonstrating that selective removal of coronary endothelium or depletion of vascular smooth muscle cyclic guanosine monophosphate markedly reduces the relaxation response to bradykinin stimulation in porcine microvessels. Linz, Martorana, and Schlekens ${ }^{45}$ reported that bradykinin in concentrations as low as $10^{-9} \mathrm{mmol} / \mathrm{L}$ increases CBF in a concentration-dependent manner in isolated working perfused hearts with regional myocardial ischemia. We used a bradykinin concentration of $10^{-6} \mathrm{mmol} / \mathrm{L}$, which resulted in an increase in CBF by greater than $230 \%$ before arrest. This responsiveness was maintained after preservation with a potassium concentration of 25 $\mathrm{mmol} / \mathrm{L}$, but not in high-potassium UWS. This loss of endothelium-dependent relaxation correlated with decreased NO release. Hence it appears that endothelial dysfunction is secondary to a high potassium concentration.

Optimal myocardial preservation remains a major concern in heart transplantation. Fullerton and associates $^{46}$ demonstrated coronary vasomotor dysfunction and histologic evidence of coronary vascular damage acutely after cardiac autotransplantation, which may compromise myocardial function. Furthermore, in the long term, this could contribute to the development of graft coronary artery disease. ${ }^{46}$ Our previously published data showed a significantly lower prevalence of cardiac allograft vasculopathy in hearts preserved with Stanford solution compared with hearts in the UWS group at 24 months of mean follow-up. ${ }^{47}$ Other investigators have correlated endothelial dysfunction with graft atherosclerosis. ${ }^{48,49}$ This might be important in the progression of accelerated graft atherosclerosis in human heart transplantation. Further investigation is being done to evaluate the long-term effects of endothelial dysfunction, induced by high-potassium UWS, on the development of accelerated graft coronary artery disease.

1. Wahlberg JA, Southard JH, Belzer FO. Development of a cold storage solution for pancreas preservation. Cryobiology $1986 ; 23: 477-82$. 
2. D'Allessandro AM, Stratta RJ, Sollinger HW, et al. Use of UW solution in pancreas transplantation. Diabetes 1989; 38(suppl 1):7-9.

3. Henery ML, Sommer BG, Ferguson RM. Improved immediate function of renal allografts with Belzer perfusate. Transplantation 1988;45:73-5.

4. Kalayoglu M, Sollinger HW, Belzer FO, et al. Extended preservation of the liver for clinical transplantation. Lancet 1988;1:617-9.

5. Breda MA, Drinkwater DC, Laks H, et al. Successful longterm preservation of the neonatal heart with a modified intracellular solution. J Thorac Cardiovasc Surg 1992;104: 139-50.

6. Swanson DK, Pasaoglu I, Berkoff HA, Southard JH, Hegge JO. Improved heart preservation with UW preservation solution. J Heart Transplant 1988;7:456-67.

7. Stein DG, Permut LC, Drinkwater DC, et al. Complete functional recovery after 24-hour heart preservation with University of Wisconsin solution and modified reperfusion. Circulation 1991;84(Suppl):III316-23.

8. Yeh T Jr, Hanan SA, Johnson DE, et al. Superior myocardial preservation with modified UW solution after prolonged ischemia in the rat heart. Ann Thorac Surg 1990;49:932-9.

9. Stein DG, Drinkwater DC, Laks H, et al. Cardiac preservation in patients undergoing transplantation. J Thorac Cardiovasc Surg 1991;102:657-65.

10. Jeevanandam V, Barr ML, Auteri JS, et al. University of Wisconsin solution versus crystalloid cardioplegia for human donor heart preservation. J Thorac Cardiovasc Surg 1992; 103:194-9.

11. Follette DM, Buckberg GD, Mulder DG, Fonkalsrud EW. Deleterious effects of crystalloid hyperkalemic cardioplegic solutions on arterial endothelial cells. Surg Forum 1980;31: 253-5.

12. Carpentier S, Murawsky M, Carpentier A. Cytotoxicity of cardioplegic solution: evaluation by tissue culture. Circulation 1981;64(Suppl):II90-5.

13. Mankad PS, Chester AH, Yacoub MH. Role of potassium concentration in cardioplegic solutions in mediating endothe lial damage. Ann Thorac Surg 1991;51:89-93.

14. Saldanha C, Hearse DJ. Coronary vascular responsiveness to 5-hydroxytryptamine before and after infusion of hyperkalemic crystalloid cardioplegic solution in the rat heart. J Thorac Cardiovasc Surg 1989;98:783-7.

15. Cartier R, Hollman C, Dagenais F, Buluran J, Pellerin M, Leclerc Y. Effects of University of Wisconsin solution on endothelium-dependent coronary artery relaxation in the rat. Ann Thorac Surg 1993;55:50-6.

16. Keller MV, Geddes L, Spotnitz W, Kaul S, Duling BR. Microcirculatory dysfunction following perfusion with hyperkalemic hypothermic cardioplegic solution and blood reperfusion. Circulation 1991;84:2485-92.

17. Shimokawa $\mathbf{H}$, Vanhoutte PM. Impaired endothelium-dependent relaxation to aggregating platelets and related vasoactive substances in porcine coronary arteries in hypercholesterolemia and atherosclerosis. Circ Res 1989;64: 900-14.

18. Bassenge E, Busse R. Endothelial modulation of coronary tone. Prog Cardiovasc Dis 1988;30:349-80.

19. Ignarro LJ, Byrns RE, Buga GM, Wood KS. Endotheliumderived relaxing factor from pulmonary artery and vein possesses pharmacologic and chemical properties identical to those of nitric oxide radical. Circ Res 1987;61:866-79.
20. Cohen RA, Shepherd JT, Vanhoutte PM. Inhibitory role of the endothelium in the response of isolated coronary arteries to platelets. Science 1983;221:173-4.

21. Lerman A, Burnett JC Jr. Intact and altered endothelium in regulation of vasomotion. Circulation 1992;86(Suppl): III12-9.

22. Born GVR. Platelets and blood vessels. J Cardiovasc Pharmacol 1984;6:S707-13.

23. Drinkwater DC Jr, Ziv ET, Laks H, et al. Extracellular and standard University of Wisconsin solutions provide equivalent preservation of myocardial function. J Thorac Cardiovasc Surg 1995;110:738-45.

24. Pearl JM, Laks H, Drinkwater DC, et al. Loss of endothelium-dependent vasodilation and nitric oxide release after myocardial protection with University of Wisconsin solution. J Thorac Cardiovasc Surg 1994;107:257-64.

25. Belzer FO, Southard JH. Principles of solid-organ preservation by cold storage. Transplantation 1988;45:673-6.

26. Gharagozloo F, Bulkley BH, Hutchings GM, et al. Potassium-induced cardioplegia during normothermic cardiac arrest. J Thorac Cardiovasc Surg 1979;77:602-7.

27. Sellke FW, Shafique T, Schoen FJ, Weintraub RM. Impaired endothelium-dependent coronary microvascular relaxation after cold potassium cardioplegia and reperfusion. J Thorac Cardiovasc Surg 1993;105:52-8.

27a. He GW, Yang CQ, Rebeyka IM, Wilson GJ. Effects of hyperkalemia on neonatal endothelium and smooth muscle. J Heart Lung Transplant 1995;14:92-101.

28. Metha JL, Nicholas WW, Donnelly WH, Lawson DL, Saldeen TGP. Impairment of canine coronary response to acetylcholine and bradykinin after occlusion and reperfusion. Circ Res 1989;64:43-54.

29. Rubanyi GM, Vanhoutte PM. Superoxide anions and hyperoxia inactivated endothelium derived relaxing factor. Am J Physiol 1986;250:H822-7.

30. Nakanishi K, Zhao Z, Vinten-Johansen J, Lewis JC, McGee S, Hammon JW. Coronary artery endothelial dysfunction after global ischemia, blood cardioplegia, and reperfusion. Ann Thorac Surg 1994;58:191-9.

31. Qui Y, Manche A, Hearse DJ. Contractile and vascular consequences of blood versus crystalloid cardioplegia in the isolated blood perfused rat heart. Eur J Cardiothorac Surg 1993;7:137-45.

32. Lefer AM, Tsao PS, Lefer DJ, Ma XL. Role of endothelial dysfunction in the pathogenesis of reperfusion injury after myocardial ischemia. FASEB J 1991;5:2029-34.

33. Amrani $\mathrm{M}$, Ledingham S, Jayakumar J, et al. Detrimental effects of temperature on the efficacy of University of Wisconsin solution when used for cardioplegia at moderate hypothermia. Circulation 1992;86(Suppl II):II282-8.

34. Amrani M, Manchad PS, Yacoub MH. Improved preservation of endothelial function at $4^{\circ} \mathrm{C}$. Eur J Cardiothorac Surg 1992;6:72-8

35. Aoki M, Kawata H, Mayer JE Jr. Coronary endothelial injury by cold crystalloid cardioplegic solution in neonatal lamb. Circulation 1992;86(Suppl):II346-51.

36. Mankad PS, Slavik Z, Yacoub M. Endothelial dysfunction caused by University of Wisconsin preservation solution in the rat heart: the importance of temperature. J Thorac Cardiovase Surg 1992;104:1618-24.

37. Evora PRB, Pearson PJ, Schaff HV. Crystalloid cardioplegia and hypothermia do not impair endothelium-dependent relaxation or damage vascular smooth muscle of epicardial 
coronary arteries. J Thorac Cardiovase Surg 1992;104:136574.

38. Sawatari K, Kadoba K, Bergner KA, Mayer JE. Influence of initial reperfusion pressure after hypothermic cardioplegic ischemia on endothelial modulation of coronary tone in neonatal lambs. J Thorac Cardiovasc Surg 1991;101:777-82.

39. Mitchell JA, de Nucci G, Warner TD, Vane JR. Different patterns of release of endothelium-derived relaxing factor and prostacyclin. Br J Pharmacol 1992;105:485-9.

40. Furchgott RF, Zawadski JV. The obligatory role of endothelial cells on the relaxation of arterial smooth muscle by acetylcholine. Nature 1980;288:373-6.

41. Palmer RMJ, Ferrige AG, Moncada S. Nitric oxide release accounts for the biochemical activity of endothelium-derived relaxing factor. Nature 1987;327:524-6.

42. Welch G, Loscalzo J. Nitric oxide and the cardiovascular system. J Card Surg 1994;9:361-71.

43. Seale NR, Salab P. Endothelial vasomotor regulation in health and disease. Can J Anaesth 1992;39:838-57.

44. Sellke FW, Shafique T, Schoen FJ, Weintraub RM. Impaired endothelium-dependent coronary microvascular relaxation after cold potassium cardioplegia and reperfusion. J Thorac Cardiovasc Surg 1993;105:52-8.

45. Linz W, Martorana PA, Schlekens BA. Local inhibition of bradykinin degradation in ischemic hearts. J Cardiovasc Pharmacol 1990;15(suppl 6):S99-109.

46. Fullerton DA, Mitchell MB, McIntyre RC, et al. Mechanism of coronary vasomotor dysfunction in the transplanted heart. Ann Thorac Surg 1994;58:86-92.

47. Drinkwater DC, Rudis E, Laks $H$, et al. University of Wisconsin versus Stanford cardioplegia and the development of allograft vasculopathy. J Heart Lung Transplant 1995;14:891-6.

48. Ignarro LJ. Biological actions and properties of endothelium derived nitric oxide formed and released from artery and vein. Circ Res 1989;65:1-21.

49. Mellion BT, Ignarro LJ, Ohlstein EH, et al. Evidence for the inhibitory role of guanosine 3,5-monophosphate in ADP induced human platelet aggregation in the presence of nitric oxide and related vasodilators. Blood 1981;57:946-55. 